\title{
Areas of Focus in Designing Online Platforms for SOCIAL INNOVATION DIFFUSION
}

\author{
Diana Elena Gaftoneanu \\ Malmö University, Sweden
}

\begin{abstract}
From the starting point of existing online platforms that provide collections of social innovations and, through their actions, encourage the diffusion of their featured initiatives, the purpose of this paper is to put forward a set of areas of focus that, if implemented, would form the basis of an online platform tailored specifically to accommodate and foster social innovation diffusion. With a focus on grassroots social innovations that cater to citizens' everyday needs, existing platforms are analysed through relevant theory on diffusion and design for social innovation, drafting three main areas of focus: creating an enabling environment, offering flexible entries and ensuring the visibility of adaptations. These areas are then detailed, supported by examples and possible paths to follow, concluding with a call for further research and an invitation to start a conversation about the need to design and develop online platforms for social innovation diffusion.
\end{abstract}

Keywords: Social Innovation, Diffusion, Online Platform, Adaptability, Context Consideration, Citizen Empowerment

$\mathrm{T}$ This paper is based on the findings from Gaftoneanu's previous work (2016) which explores the defining features of online platforms in terms of their potential to aid the diffusion of social innovation. For the purpose of this paper, social innovation is understood both as outcome and process, following the European Commission's definition according to which social innovations represent the "development and implementation of new ideas to meet social needs and create new social relationships and collaborations" (Policy, 2013:3).

Diffusion, another key term in this paper, refers to the social innovation process step that, alongside scaling, leads towards social and systematic change (Murray, Caulier-Grice \& Mulgan, 2010: 12-13). As diffusion alludes to personal rather than organizational efforts of spreading social innovations, careful consideration of context is required, from geographical adaptability to compatibility with value systems (Davies \& Simon, 2013). The complexity of social innovation diffusion lies in its "flow-like process of interaction and modification" (Murray et al., 2010:82), chaotic spread and lack of linearity and rationale (Davies \& Simon, 2013).
Platforms that offer collections of best-case practices or ongoing initiatives with a social outcome are an important contributor to the wide spread of social innovations in recent times. The platforms with the widest outreach are the ones that use ICT and specifically the internet as a means to spread knowledge. Murray et al. (2010:95) defines them as "the nodes of a new economy, and other ways in which users and originators can engage in the evaluation and adaptation of innovations" whilst a more precise definition comes from the European Commission which refers to such platforms as Collective Awareness Platforms for Sustainability and Social Innovation (CAPS). CAPS, according to Armani et al. (2014:9) are "ICT systems leveraging the emerging network effect by combining open online social media, distributed knowledge creation and data from real environments in order to create awareness of problems and possible solutions requesting collective efforts, enabling new forms of social innovation". Regardless of how they are referred to, many of these platforms recognize the importance of social innovation diffusion and, though it is not necessarily in their stated purpose, the features they offer support the diffusion process. 


\section{Areas of Focus}

The purpose of this paper is to put forward a set of areas of focus that can act as the basis for potential online platforms built around the process of social innovation diffusion. By taking a closer look at several existing online platforms which, albeit often indirectly, aid the diffusion of social innovations, and contrasting them with relevant theory on diffusion and design for social innovation, the following areas of focus were drafted:

- enabling environment

- flexible entries

- visibility of adaptations

These areas of focus do not presume to be anything more than thought-provoking proposals, in the hopes of opening and encouraging conversation and inviting further research into the matter. Though inspired by a wide variety of existing platforms, the areas are presented in the context of a conceptualized online platform specifically designed for the purpose of aiding social innovation diffusion.

Special attention is also given to what types of social innovations the following areas of focus cater to. Existing online platforms address a whole spectrum of social innovations, from daily concerns of urban citizens, to activism or even tackling some of the Millennium Development Goals. According to Everett Rogers' theory on diffusion of innovations, easy to understand, compatible and straightforward innovations increase rates of adoption, whilst the ability to have them changed or modified by the user in the process of adaptation and implementation makes the innovations easier to be diffused (Rogers, 2003:17). Murray et al. (2010) make similar remarks about social innovations, noticing a higher diffusion rate of simple, modular innovations that do not require new skills to be adapted. It is with this in mind that the areas of focus argued for below revolve around the diffusion of social innovations addressing problems of everyday life. ${ }^{1}$

Whether they are referred to as social innovations in the household economy (Murray et al., 2010), everyday diffused social enterprises and creative communities (Jegou \& Manzini, 2008; Meroni, 2007) or grassroots social innovations to name a few, there is a clear movement of innovations stemming from active citizens that become aware of needs or opportunities in their communities and put forward innovative initiatives, creating social value in both their process and outcome.

${ }^{1}$ Throughout the paper, the social innovations for which the areas of focus are proposed are referred to as grassroots social innovations, proven solutions or innovative initiatives.
Distinct from social enterprises or governmental institutions, this type of social innovations are known to loosely collaborate with them if the case be. Lastly, the social innovations for which the areas of focus are designed, through their local community nature, direct citizen interaction and catering to everyday needs, require few resources in terms of time, money, technology, people or skills needed for their implementation.

\subsection{Enabling Environment}

The way social innovations are portrayed and the levels of interaction offered to users vary greatly across platforms. A typical approach is presenting the social innovation as a product that the user can support in various ways. MakeSense (2016) offers the possibility for social entrepreneurs to pose their ideas and needs on which users can act through organizing hold-ups ${ }^{2}$, joining existing ones or leaving messages and ideas on the inspiration wall. Similarly, Red Bull's Amaphiko platform allows users with accounts to add their projects or contribute to the projects featured by offering their skills, which can range from fundraising to professionspecific tasks such as marketing, graphic design, web development or accounting (Amaphiko, 2016). Ioby, an online platform for neighbourhood level social innovations, follows the presentation of the project with a crowdfunding option, as well as the ability to volunteer for the user's neighbourhood projects (Ioby, 2016).

What these examples have in common is a red thread of pitching a project and receiving help and support from a community. The project originator holds a specifically important position and can be anyone from citizens to social entrepreneurs or organizations, with some platforms, such as Red Bull's Amaphiko, inquiring about details like the legal status and developmental stage of the project when submitting a new entry (Amaphiko, 2016). In other cases, reducing the importance of the project originator (i.e. less information required, no need to create a user account) correlates with the reduced relevance of the entry on the platform, for example by not offering the possibility for potential implementers to interact with these entries. CIVICS is one such platform where anyone can enter a project or initiative that is taking place in their community which becomes visible for all through crowdmapping, but with no option of directly interacting with the entry via the platform (CIVICS, 2016).

\footnotetext{
${ }^{2}$ Hold-ups are 2 hour workshops aimed to help social entrepreneurs develop their initiative (MakeSense, 2016).
} 
There is incontestable benefit in making a large variety of social innovations public and engaging the audience to somehow get involved in these initiatives. Nonetheless, when it comes to grassroots social innovation, though some eventually turn into social enterprises or take different forms, a large part of them remain within the community or spread through the weaker ties of the community to new ones, in a natural, chaotic dissemination process. In the case of an online platform built for the purpose of diffusing such ideas as opposed to the growth or maintenance of a social enterprise, more attention should be given to the relationship that the user and originator of the idea have with each other, the innovation and the platform respectively.

Keeping in mind that the individual is at the basis of the diffusion process when compared to scaling, the first area of focus that this paper puts forward is creating an enabling environment for users by changing the focus from the social entrepreneur or originator of the idea to the future implementer. Designing the platform with the implementer as the main character of the diffusion process can be done by passing over the control to $\mathrm{him} /$ her when it comes to entries and their functionality, tailoring social innovations to cater to the user's needs whilst empowering him/her to take ownership of the diffusion process.

Vivero de Iniciativas Ciudadanas (VIC), an online platform that looks to promote, diffuse and support citizen initiatives (VIC, 2016), offers an editable collection of social innovations by using wikis, thus encouraging any user to edit and adjust the featured entries. According to Scearce, Kasper and Grant (2010), wikis and other networking tools work best in an environment where power is pushed to the edges, prioritizing trust, openness and transparency, thus allowing people to selforganize and diffuse information. On a platform designed for minimum implication of external influencers and for decentralization, users can take both the role of originator of the idea and implementer of an existing entry, thus blurring the boundaries between the two.

Other elements, such as free, non-restrictive access, can contribute as well to increasing the diffusion potential of the online platform by reaching wider audiences. The inclusion of a fee for online platforms is often necessary for its sustainability but it also reduces the number of its potential users. Meetup is a great example of an online platform that enables neighbours to organize meetups with the purpose of sharing and learning (Meetup, 2016). Nonetheless, accounts are needed to join or organize a meetup in your neighbourhood, and the associated monthly fees for organizing are only revealed once a whole new entry is filled in.

Further on, offering support for the implementer throughout the diffusion process plays a crucial role in creating an enabling environment. Everett Rogers talks about the five stages of the innovation-decision process, from learning about an innovation, to forming an attitude towards it, deciding to adopt it, putting it to use and finally seeking reinforcement for one's decision (Rogers, 2003). With the main focus around the implementer, the platform would need not only to offer information that sparks curiosity and interest, but also support the user throughout the rest of the innovation-decision process.

In the knowledge stage, the user discovers the innovation that addresses his/her needs or interests and gathers information about what it consists of and its functionality (Rogers, 2003). The information should be structured and presented keeping in mind the end reader. In this sense, filters, keyword search and suggested entries based on location are some of the manners in which the user can find suitable solutions. In terms of the information offered, alongside the description of the solution and the problem it answers, the context and potential questions the user may have should be addressed as well.

Shareable's "how to's" are good examples of short presentations and loose rules of implementations for popular grassroots social innovations, most commonly written by the original implementers of the ideas (Shareable, 2016a). Though one of few which tailors to the needs of the future implementer, there is no possibility to contribute or interact with the entries, nor to give feedback on potential questions that might arise.

In the case of the persuasion stage, Rogers (2003) stresses the importance of subjective evaluations when it comes to considering adapting a certain innovation. Knowing the status of the innovation, its success and other people's experiences related to it can guide the user in taking a decision regarding its implementation.

Citymart, an online platform which focuses on government-to-government social innovation exchange, used to have a publicly available database of their solutions including their track record, covering, among others, how many times a solution was successfully adopted by other governments and including photos and videos to support their claims (Citymart, 2016). Apps4citizens, an online platform that promotes mobile applications for collective social and political engagement, offers for each entry a list of advantages and disadvantages, as well 
as personal opinions from former users and scores for content and functionality, social and political impact, design and usability, and innovation (Appteca, 2016). Whereas in the case of Citymart the track record is automatically generated, Apps4citizens's evaluations are based on "expert" entries, representing other users of the platform that have previously used the mobile application in cause (Citymart, 2016; Appteca, 2016).

The decision stage can also be actively integrated in the platform, offering needed tools and features for the adaptation and implementation of the entry. Individual adaptable duplicates of social innovations that are being implemented in different contexts allow the user to adapt an entry to his/her own needs, encouraging the success of the implementation.

Due to the offline local nature of the grassroots social innovations, the implementation stage of the innovation-decision process often takes place outside the premises of the platform, though support should still be offered for inspiration or potential problems that could arise ${ }^{3}$. In relation to the confirmation stage, within which the user acknowledges the level of success of the implementation and further promotes it (Rogers, 2003:199), Von Hippel (2005) remarks the tendency of users to reveal and discuss their contributions and input in a certain innovation in their search for suggestions for improvements, thus working towards a common benefit whilst going against the expected action of claiming ownership and patenting their contributions. Some of the ways in which the platform could build on and integrate this tendency is though keeping a track record of the innovation and offering the ability to add materials documenting the implementation or support other similar adaptations. In the case in which the user is the originator of the initiative, it is in this stage that he/she is encouraged to share his/her experiences on the platform.

\subsection{Flexible Entries}

Due to the widespread accessibility of the internet, most online platforms have the potential to reach a global audience. Nonetheless, despite their availability in English, global lingua franca, the majority of online platforms offering social innovation collections promotes initiatives originating or being funded and supported by the Global North. Priya and Marras (2008:133) notice the tendency to transplant Northern solutions in emerging econo-

\footnotetext{
${ }^{3}$ Suggestions for how this support can be integrated in the platform are offered in the following sections.
}

mies, sometimes at the cost of better local options embedded in centuries of tradition and experience. It is important to remark as well that grassroots innovations do not depend on the development stage of the country or its geographical location. Jegou and Manzini (2008:34) note in this sense that ideas and experiences can move in all directions, including back and forth between the Global South and North.

Acknowledging this potential and "building a two-way bridge" between the two worlds could greatly enrich the existing diversity of grassroots social innovations (Gaftoneanu, 2016). Nonetheless, such transfer is not always straightforward. In a modern post-industrial Europe where people are aware of their individualistic lifestyle, grassroots social innovations focus on areas such as community solidarity, whilst such actions in emerging economies are part of daily life, when their needs revolve around different social issues (Priya \& Marras, 2008:136).

Moreover, a truly global reach is debatably unachievable due to technological, economic and cultural limitations, from the great firewall of China to first and second digital divides (MacKinnon, 2011). These said, there is still untapped potential when it comes to diffusing social innovations in different parts of the world, as well as in harnessing the individual local knowledge of implementers to be able to adapt a social innovation to their specific needs.

Waitzer and Paul (2011:144) make an important observation when it comes to the scalability of social innovations as opposed to business ideas, stating that because of their social nature, the majority of such initiatives remain local, so the focus should be changed from trying to scale them, to instead scaling their impact, allowing ideas to travel. Locality should be understood in this sense as a balance between "being rooted in a given place and being open to global flows of ideas, information and people" (Manzini, 2015:202).

Jegou and Manzini (2008:111) further argue for the benefits of the social innovations' local character and the need to make them more accessible whilst preserving their original quality and appeal that are essential to insure the success of the solution when implemented by adopters with differing socio-demographic profiles. Keeping the local character of social innovations when diffusing across borders represents a daunting task which requires a heightened context awareness and adaptability.

Diffusion of social innovations constantly occurs naturally among individuals from different backgrounds, suffering changes and modifications 
throughout this process. To stimulate diffusion, Priya and Marras (2008:136) note that social innovations "have to be sensitive to social, cultural and economic differences and be based on local priorities and feasibility" whilst Weber, Kröger and Lambrich (2012) stress the undermining of cultural differences when it comes to scaling social innovation. With all this in mind, the importance of context adaptability becomes evident.

The second area of focus stems from acknowledging the balance needed between local character and global reach as well as the need for adaptability, proposing flexible entries that take the context of the implementer into consideration.

To better understand this flexibility, a closer look needs to be taken at the structure of a social innovation entry. Due to deep local roots and strong dependence on its originators, grassroots social innovations suffer changes throughout the adoption process. Nonetheless, the idea behind the individual adaptations created is often selfstanding. Following this line of thought, Manzini observes that when talking about diffusing a social innovation, the discussion can be formulated as "how these ideas may spread and how different groups of people may recognize, adopt and localize them" (2015:180).

To enable contextual consideration for different instances of social innovations, a popular option is developing toolkits. Amplifying Creative Communities (2016), whose activities include "broadcasting good ideas for others to adopt" offer specialized packages of tools for potential implementers of a specific idea called "Recipes for Change" . Though successful when properly implemented, creating toolkits is a time and resource consuming activity, keeping in mind that they are specially tailored for a small number of social innovations. This, in turn, prompts for an option that would allow context adaptability for a large range of social innovations.

Catch 22, in their focus piece offering insights for the ongoing Realising Ambition Programme, propose a hypothesis in which the innovation to be replicated is split between its core, representing the key elements of the initiative that address the need or opportunity under discussion, and the adaptable surface, comprising of flexible elements that could be moulded according to the context and characteristics of the implementer (Realising Ambition, 2015). This distinction, as well as the degree of the changes needed, may be dictated and then moulded by the user, in an attempt to simulate how the

\footnotetext{
${ }^{4}$ http://www.amplifyingcreativecommunities.org/ RecipesforChange.pdf
}

diffusion process would take place outside the online platform.

Face-to-face interaction, community involvement, resource availability and several other external influences are encouraged, both in terms of protecting the local quality of the social innovation and offering complementary support for implementers, outside the platform's reach.

By preserving the core of the social innovation, the value behind the solution is maintained, allowing the rest of the elements to be adapted across different geographical, cultural, political or religious boundaries by those who understand the context best: the users themselves. Online platforms featuring flexible entries would be a strong step forward towards facilitating social innovations to cross borders and diffuse globally. Further research is needed in order to better understand how entries on the online platform should be presented to ensure the user's comprehension and involvement in accordance with his/her context.

\subsection{Visible Adaptations}

As argued above, though locality is a key feature of grassroots social innovations, it also represents a huge downside in terms of their diffusion potential, as their relevance to the local community and lack of outside help mean that they tend to remain within the communities that initiated them.

There have been several attempts by passionate researchers to explore the diversity of grassroots social innovations and create collections of best case practices. One such example is Hand Made: Portraits of Emergent New Community Culture, a very engaging collection of unique initiatives from "Men-Sheds" to "Fallen Fruit Jam" (Britton, 2010). An online version of such work is EMUDE (Emergent User Demands for Sustainable Solutions) featuring a wide range of everyday social innovations such as the Living Room Restaurant (EMUDE, 2016). Though such collections are fascinating and insightful, they remain out of reach for most citizens, due to a lack of either information, tools or support to implement them.

Keeping in mind that the first step of diffusion is observing a new innovation and gaining interest in learning more about its functionality (Rogers, 2003), the visibility of existing proven solutions outside their originating communities is crucial to their potential to spread.

Mapping of initiatives has been widely used to promote participation or to raise awareness about existing initiatives, from the Green Map System, mapping environmentally sustainable projects since 1995 (Manzini, 2015:123) to crowdmapping 
for disaster relief (Dennenmoser, 2013). Most of the online platforms mentioned in this paper incorporate a form of mapping, from an alternative to a list-view, to designing the whole platform around a map of initiatives.

An interesting example of an online platform that focuses on mapping is Geographies of Innovation (2016), which offers a view of innovative initiatives in Barcelona, professionally analysed through different layers such as socio-demographic context, urban fabric, functional indicators and spatial organization. Focusing on fostering community involvement in mapping, Shareable's Map Jam is a two week long periodic sprint where a relatively small group of people called mapjammers gather to map social initiatives from over 80 cities at once (Shareable, 2016b). Perhaps the ideal strategy for mapping social initiatives for an online platform focused on diffusion is CIVICS' approach, where citizens are invited to enter information about initiatives and activities in their community that are later on featured on the map generated for their city (CIVICS, 2016). Such an approach actively welcomes the contribution of users not only as adapters but also as original diffusers of an idea, thus contributing to creating the feeling of ownership and subsequent engagement detailed in the first section.

Furthermore, Jegou and Manzini (2008:112) argue for how local visibility can be enhanced through search engines for users to be able to identify entries that are in their geographical proximity which, arguably, ensures a level of homophily with the implementers of those initiatives, easing a potential adaptation. Proximity features can also be used to offer the platform's users a view of social innovations that are taking place in the area. Moreover, by understanding the needs that led to those initiatives, platforms could offer suggestions for the area in terms of proven solutions that have addressed similar needs.

Besides giving visibility to such initiatives, online platforms for social innovation diffusion should maintain an ecosystem around the user that encourages an active, collaborative behaviour (Manzini, 2015:121). This can be done by widening and harvesting the benefits of mapping, which brings this paper to the third area of focus: visible adaptations.

Previous sections have discussed the ability to duplicate an original entry following the decision stage, as well as the flexibility of the surface in relation to the core. Adaptations, in this sense, refer to the duplicated original entry whose surface is edited by the new implementer, adapting it to his/her own context. By allowing this adaptations to be part of the online platform, users have the opportunity to visualize the track record of an entry, as well as how different past or current adaptations have been edited and influenced, creating an enabling environment around the potential implementer.

This added feature has the potential to also contribute to current issues of toolkits such as not being able to cater to unforeseen problems the implementer might deal with, as well as not having any way of ensuring its proper use, that could be the result of lack of knowledge or motivation (Manzini, 2015:182-184). In this sense, older adaptations could act as sources of inspiration for new ones. Users would have the ability to decide to duplicate either an original entry or a closer adaptation to their local situation, depending on its suitability.

An outcome of such connectivity is the possibility of forming communities of practice among users. Von Hippel (2005:72), in his discussion on democratizing innovation, notices that "direct, informal user-to-user cooperation" and the innovation communities it fosters increase the speed and effectiveness of innovation diffusion. Connecting implementers of different adaptations through the online platform creates a network within which users could support each other throughout the different stages of the implementation, whether it is done through chat, email or social media, incorporated in or external to the platform itself.

\section{Concluding Remarks}

From the starting point of current online platforms offering a wide range of services related to social innovation collections, this paper proposes a series of features for a conceptualized online platform built for the purpose of enabling the diffusion of social innovations, structured around three main areas of focus: creating an enabling environment, offering flexible entries and ensuring the visibility of adaptations. It is also theorized that implementing the suggestions offered in this article, in line with areas of need of existing platforms or as the basis of new platforms, would lead to a steep increase in the diffusion of featured social innovations, determined by the sheer number of engaged users, as well as by the ability to customize, improve and receive support during the implementation stages. Such a highly sought increase may in turn lead to new and interesting outcomes with consequences that deserve to be further scrutinized. 
It is also important to stress that these areas of focus represent just few of many other ways in which the development and implementation of such platforms can be tackled. More precisely, the proposed areas should be further developed, adapted and complemented by other relevant areas, depending on the character of the online platform under development. Further research is needed to ensure their validity and efficacy, as well as consolidate a model for social innovation diffusion.

Figure 1 proposes a fundament for such a model, built on the arguments and suggestions put forward by this article. For each area, the figure outlines approaches or tools based on theory and the study of existing platforms that, if implemented, would aid the diffusion process of social innovations on online platforms.

Towards developing a model for social innovation diffusion through online platforms, further case study analysis, critical reflection, and practical implementation are strongly welcomed. The latter could lead to interesting observations regarding the implications and outreach of the featured areas of focus, offering concrete data to support the proposed ideas. Furthermore, if their validity and effectiveness is proven in relation to online platforms focused around grassroots social innovations, the specific type chosen for their development, extrapolating the results or using them as a basis of discussion to be implemented for other types of social innovations could also yield very interesting outcomes. One direction could be extending the platform to accommodate social innovations with greater social impact but that also require more resources (time, money, participants, expertise, infrastructure, materials) and stronger communication efforts.

Lastly, the aim of this paper is to put forward thought-provoking ideas, thus welcoming feedback and encouraging conversation related to the need to design and develop online platforms for social innovation diffusion as well as to the implications such platforms would have in the future, from the sustainability of social innovations to new public policies, cooperation and ways of living.

Figure 1: Areas of focus in designing online platforms for social innovation diffusion

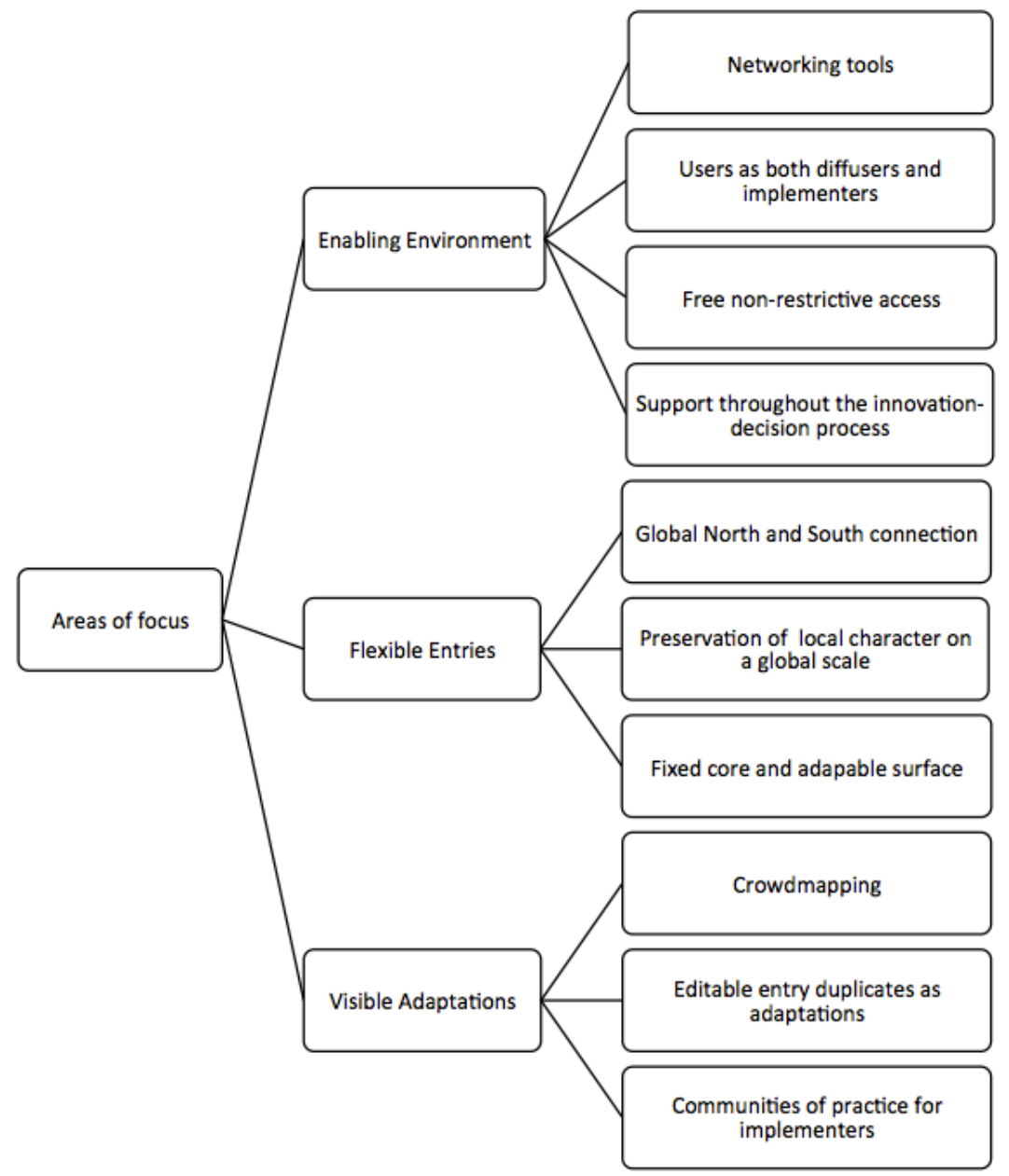

Source: Author's own elaboration 


\section{References}

Amaphiko. (2016). Needs. Retrieved from https://amaphiko.redbull.com/en/needs.

Amplifying Creative Communities. (2016). About Amplify. Retrieved from

http://www.amplifyingcreativecommunities.org/.

Appteca. (2016). Explora apps que marcan la diferencia. Retrieved from http://appteca.apps4citizens.org/.

Arniani, M., Badii,A., De Liddo, A., Georgi, S., Passani, A., Piccolo, L.S.G. and Teli, M. (2014). Collective Awareness Platform for Sustainability and Social Innovation: An introduction. Available at http://booksprints-for-ict-research.eu/wp-content/uploads/2014/07/BS5-CAPS-FIN-003.pdf .

Britton, T. (Ed.). (2010). Hande Made: Portraits of Emergent New Community Culture. Blurb Incorporated.

Citymart. (2016). Inspiring solutions. Retrieved from http://www.citymart.com/solutions/\#our-discoveryfeed.

CIVICS. (2016). Qué es CIVICS?. Retrieved from http://www.viveroiniciativasciudadanas.net/civics/iniciativas/\#a.

Davies, A. and Simon, J. (2013). Growing Social Innovation: a literature review. The theoretical, empirical and policy foundations for building social innovation in Europe (TEPSIE), European Commission7th Framework Programme. Available at http://www.tepsie.eu/images/documents/d71 final.pdf.

Dennenmoser. C. (2013). Digitising disasters: from coordinating relief to crowdmapping care. Emergency Journalism. Available at http://emergencyjournalism.net/digitising-disasters-from-coordinatingrelief-to-crowdmapping-care/.

EMUDE. (2016). Living Room Restaurant. Retrieved from http://www.sustainable-everydayproject.net/emude/2013/04/03/living-room-restaurant/.

Gaftoneanu, D. (2016). Diffusion of Social Innovations - Exploring the potential of online platforms that enable the diffusion of proven solutions. MUEP. Available at https://dspace.mah.se/bitstream/handle/2043/20265/Gaftoneanu-DE-DP15.pdf?sequence=2

Geographies of Innovation. (2016). Geographies of Innovation - map of innovative initiatives in Barcelona. Retrieved from http://innovation.300000kms.net/.

Ioby. (2016). Browse Projects. Retrieved from https://www.ioby.org/projects/browse?f[0]=sm field project status\%3A1.

Jegou, F. and Manzini, E. (2008). Collaborative services: Social innovation and design for sustainability. Edizioni Polidesign.

MacKinnon, R. (2011). China's 'Networked Authoritarianism'. Journal of Democracy, 22(2), 32-46. Available at http://muse.jhu.edu/article/427159.

Makesense. (2016). How it works?. Retrieved from https://www.makesense.org/en/pages/howitworks.

Manzini, E. (2015). Design, when everybody designs - an introduction to design for social innovation. London, England: The MIT Press.

Meetup. (2016). Start the perfect meetup group for you. https://secure.meetup.com/create/.

Meroni, A. (2007). Creative communities: People inventing sustainable ways of living. Edizioni Polidesign.

Murray, R., Caulier-Grice, J. and Mulgan, G. (2010). The open book of social innovation. National endowment for science, technology and the art. Available at https://www.nesta.org.uk/sites/default/files/the open_book_of_social_innovation.pdf.

Policy, U. (2013). Guide to Social Innovation. Available at http://ec.europa.eu/regional policy/sources/docgener/presenta/social innovation/social innovation 2013.pdf.

Priya, B-M. and Marras, I. (2008). Creative communities- their role and impact on welfare and development. Essay in: Jegou, F. and Manzini, E., Collaborative services: Social innovation and design for sustainability (pp. 133-137).

Realising Ambition. (2015). The secret life of innovation: replication. Defining success in replicating effective services for children and young people. Available at http://www.catch-22.org.uk/wp- 
content/uploads/2015/06/Realising-Ambition-Programme-Insight-The-Secret-Life-of-

Innovation.pdf.

Rogers, E. (2003). Diffusion of innovations (5th ed.). New York: Free press.

Shareable. (2016a). How to share. Retrieved from http://www.shareable.net/how-to-share.

- (2016b). \#MapJam 3.0: Join us to put Sharing on the map!. Retrieved from http://www.shareable.net/blog/mapjam-30-join-us-to-put-sharing-on-the-map.

Scearce, D., Kasper, G. and Grant, H. M. (2010). Working wikily. Standford Social Innovation Review, 8(3), 30-37.

VIC. (2016). Vivero de iniciativas ciudadanas - transferencias de la inovación ciudadana al espacio público. Retrieved from http://viveroiniciativasciudadanas.net/.

Von Hippel, E. (2005). Democratizing innovation: The evolving phenomenon of user innovation. Journal für Betriebswirtschaft, 55(1), 63-78.

Waitzer, J. M. and Paul, R. (2011). Scaling social impact: when everybody contributes, everybody wins. Innovations, 6(2), 143-155.

Weber, C., Kröger, A. and Lambrich, K. (2012). Scaling Social Enterprises-A Theoretically Grounded Framework. Frontiers of Entrepreneurship Research, 32(19), 3. 